\title{
Analysis of the Governance Models Applied in Agricultural Primary Cooperatives: The Case of Ilu Galan District, West Shawa Zone, Oromia, Ethiopia
}

Mikire Dase Boka

M.A. in Cooperative Management

Institute of Cooperatives and Development Studies

Ambo University

Ambo, Ethiopia

Motuma Hirpassa Minda

Assistant Professor in TEFL \& MA in Educational Planning and Management

Department of English Language and Literature

College of Social Science and Humanities

Ambo University, Ambo, Ethiopia

maldamercy@yahoo.com

S. Nakkiran

Professor in Institute of Cooperatives and Development Studies

Ambo University Ambo

Ethiopia 


\section{Abstract}

Prompted by increased concern about cooperative governance, the study was conducted to analyze the governance architecture, the governance models applied and the factors determining the choice of the application of the models using data obtained from 114(99 male and 15 female) respondents from four of Primary Agricultural cooperatives in Ilu Galan District. The study focuses on the governance architecture, six governance models (Democratic, Compliance, Partnership, Cooptation, Stakeholder and Rubber Stamp) and determining factors thematically organized in to seven themes: Teaming, leadership, Conflict of interest, Unnecessary intervention, legal, governance and education/training. The data analysis was made using descriptive statistics: percentage of frequency, weighted mean, standard deviation and ranking methods. The results identified that primary Agricultural cooperatives in the District have the poorly adapted governance architecture, which cannot clearly show the governance framework or the four pillars (accountability, transparency, predictability and participation) and strategic leadership activities (the vision, mission, objectives and activities to be achieved in their plan and bylaw). The cooperatives hardly apply the principles of cooperatives in general and that of governance models in particular. Democratic, Co-optation, Rubber Stamp Models were the top three models that Primary Agricultural Cooperatives were implementing in the District. The data analyzed show that almost all the members of the cooperatives were confused with word "model" as a result of which governance related factors, lack of awareness/education/training, Teaming and strategic leadership factors were the first four important factors in influencing the choice of the application of Cooperative Governance Model to Primary Agricultural Cooperatives in the District. Therefore, the prescriptions for the cure also lie in bringing about improvement in these factors. 
Key Terms: Agricultural primary Cooperatives, Cooperative Governance Models, Pillars of Governance.

Introduction

Cooperative is an autonomous association of persons united voluntarily to meet their common economic, social and cultural needs and aspirations through a jointly owned and democratically controlled enterprise. The people of Ethiopia have got a very long social history of working together to fulfill their socio-economic needs. Agriculture, Trade and Military Operations were carried out through cooperative efforts. Cooperative in Ethiopia is defined as an association of persons who have voluntarily joined together to a common end through the formation of a democratically controlled organization, making equitable contribution to the capital required and accepting a fair share of the risks and benefits of the undertaking, in which the members actively participate. Cooperation among people of Ethiopia has existed since time immemorial. Hence, cooperative as a legal institution first came in to being in Ethiopia in 1960's. During the socialist government, i.e., the Derg regime (1974-1991), cooperatives were formed to assist implementation of the government policy of collective ownership of properties. It was then triggered by reforms to the socio-political system.

Many social events are still taking place in Ethiopia through collective effort. The current Federal Government of Ethiopia has also identified cooperative form of business organizations as an instrument of socio-economic change particularly to achieve food security. As a result, the country has recorded 6004 Primary Agriculture in 2006 and Allied Cooperatives to serve the suppressed and depressed community of Ethiopia. To this end, cooperative governance is the heart of system to actively participate the members in cooperatives' activities. This needs a detailed study. Current government of Ethiopia, however, 
issued different proclamations, policies and strategies to revitalize cooperatives (Proclamation85/1994) and to reinforce these principles and strengthen membership incentives by improving members 'rights in the areas of ownership, voting, share transfers, and risk management (Proclamations 147/1998 and 402/2004). In a related but slightly different vein, the owners, the board and the management of cooperatives are known as the governance team. Combining these notions, the cooperative consists of four main players: owners, board, an executive and staff. In its broadest sense, this is the model. As we move further down this path and try to define further layers of this model, we find discussion around three main themes: the who of governance (structure or division of work), the why of governance (motive and behavior) and the "what to do "of governance (prescription and best practice).

As analyzed by Lees (1995), Lees and Volkers (1996) and Cornforth (2004), Cooperatives Governance Models include: Democratic Model, Compliance Model, Partnership Model, Co-optation Model, Stakeholder Model and Rubber Stamp Model. In the literature, dealing with governance, the word "model" is a confusing, overlapping and often misleading term. A model is a framework or approach may be formulated in theoretical, functional, institutional, or behavioral terms. However, to be useful, it must serve as a guide for members; it must be prescriptive. By model, Carver (1970) means "a collection of principles and concepts that makes sense as a whole". In this context, model is "principles of governance" that might be better terminology than the word "model" because there should be "a logical, deductive sequence built on postulates". Therefore, in this paper "governance model" has been defined as a" distinctive set or cluster of governance structures, responsibilities (functions) and processes (practices) that are logically consistent with one another". As a result, this study is intended to assess the implementation of the common characteristics of all the six Cooperative Governance Models to Agricultural Cooperatives in 
Ilu Galan District, West Shawa Zone, Oromia, Ethiopia.

\subsection{Statement of the Problem}

The instrumental nature of governance models implies the governance pillars (accountability, transparency, predictability and participation) which are universally applicable regardless of the economic orientation, strategic priorities, or policy choice of the cooperatives (Gupta, Verhoeven and Tiongson, 2002; Filmer and Pritchett, 1999; Castro Leal et al., 2000; Canagarajah and Ye, 2001). However, inappropriate implementation of the cooperative models/principles can cause the deterioration of honesty, ineffectiveness of cooperatives, inactive participation and less mutual benefits for one another among members. Hence, the failure of democratic governance and the recent years increase in corruption across the cooperative societies in Ethiopia has witnessed the crisis and collapses for many cooperative. Members of some cooperatives in the study area informally expressed that cooperative governance systems are being devoted for political affiliations rather than members' socio-economic problems. As a result, they are dissatisfied with their cooperatives' governance activities in making equitable contribution to the capital required and accepting a fair share of the benefits of the cooperatives. As to the member, limitation of governance is negatively affecting the willingness and confidence of the members to continue as the members of the cooperatives. Moreover, the members of the cooperatives were unexpectedly resigning from the membership of cooperatives. Evidently, a report made by Ilu Galan Woreda cooperative office in 2006 indicated that 98(32.88\%) member were left from four Agricultural cooperative within the last two years. Moreover, two agricultural primary cooperatives were collapsed. This has led to surging up questions about the quality of the implementation of governance principles (the structure or division of work and the prescription and practice) among different managing committees and the members of the cooperatives. 
Therefore, the main problem for the study was the confusions to implement the effective governance models applied to the Agricultural primary cooperative. These could include the governance failure to identify and implement the appropriate structure or division of work, the motive and behavior and the prescription and practice of different management bodies and members of cooperatives in Ethiopia in general and in the District in particular. In other words, three paradoxes: the "who governs", the "board roles" and the "relationships with management" had been identified as the concern for the study because boards, managements bodies and members of the agricultural primary cooperative were not clear in adapting governance system and applying relevant governance models/principles based on their unique and distinctive purpose and work patterns to their cooperatives. In addition, although the principles of cooperative states that cooperative organizations need to be democratically controlled, there were observable problem of mismanagement and financial scandals in some cooperatives societies.

Objectives of the Study

1. To explore the governance architecture in primary agricultural cooperatives in Ilu Galan District.

2. To analyze governance models applied in primary agricultural cooperative in Ilu Galan District.

3. To examine the factors those determine the choice of application of governance models in selected cooperatives in Ilu Galan.

\section{Basic Research Questions}

The study was intended to answer the following questions. 
1. Have Agricultural primary cooperatives in Ilu Galan District adapted governance system including the four pillars of cooperative governance: Accountability, Transparency, Predictability and Participation?

2. Which cooperative governance models do Agricultural Primary Cooperatives dominantly implement?

3. What are the factors that determine the choice of application of certain governance models in Agricultural primary cooperative in Ilu Galan District?

Conceptual Frame of the Study

The following diagram shows the conceptual frame of the study.

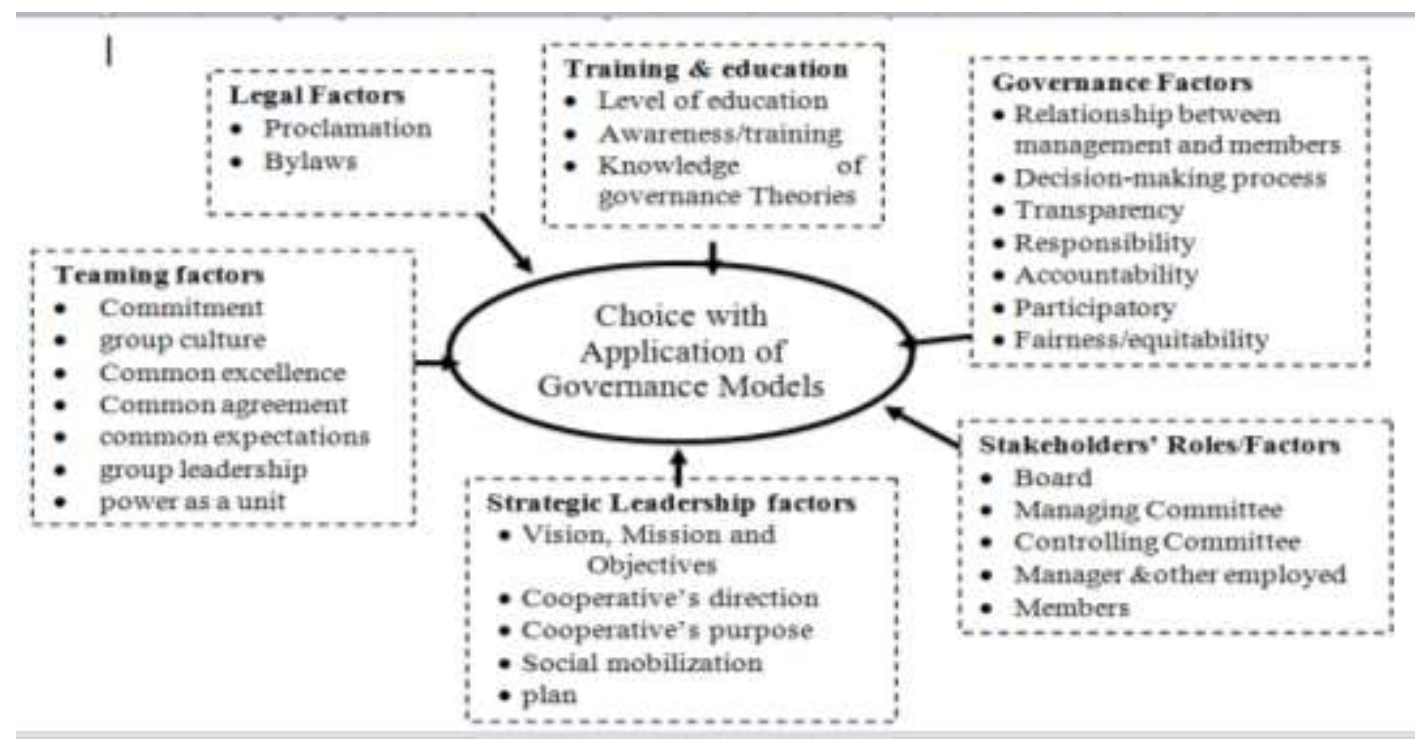

Figure 1: Factors Determining the Choice with application of governance Models

Figure 1 illustrates the cooperative stakeholders' choice with application of governance Models. Normally cooperatives have different choices of applying various models of governance to govern their affairs. In this context, the dependent variables as categorical variable have more than two outcomes as choices. The governance models applications choice would be: models based on structure or function (the who of governance); models 
based on motives or behavior (the why of governance) and/or models based on prescription and best practices (what to do of governance). In other words, this can be stated as Carver (1970) as: "who of Governance", "why of governance" and "what to do governance". In the same token, this refers to the analysis of the role the management, members, non-members play in the governance of co-operative and the issues influencing them to choose certain types of governance models.

On the other hand, the figure also demonstrates the independent variables. These include: legislations/ legal frameworks (the physical presence and effective implementation of Legal frameworks like bylaws and others); training and education level (the awareness and education level of member owners, Board, GM/CEO, staff to implement the legal matters of the cooperatives and the economic, social, and cultural success of them), democracy (transparence, fairness and social mobilization of member owners, Board, GM/CEO and Staff in ensuring timely, protect stakeholders' right, practice, promote, perpetuate and treat all stakeholders equitably. Moreover, it also includes strategic leadership (strategic leadership to implement vision, mission and objectives of the cooperative governance models, legal matters of the cooperatives and the economic, social, and cultural success of them), teaming (how stakeholders are working together and individually to achieve common purpose) and accountable empowerment (ability to get things done and to be effective through delegation based on clear expectations, assigning responsibility and checking).

\section{Research Design and Methodology of the Study}

To assess the models of governance used in Agricultural Primary Cooperative society in the study area, survey research design was used. This type of research design helped the researchers to achieve a comprehensible understanding of evidence on the experience of cooperative governance models (Johnson, Onwuegbuzie \& Turner, 2007). Besides, a 
descriptive survey research design is helpful to identify present conditions and point out present needs of governance. It is also useful in showing the immediate status of governance phenomenon (Sharma, 2000). In other words, the study utilized both quantitative and qualitative methods to elucidate the implementation of cooperative models and thereby, enables the researcher to collect valuable data from primary (owners/members, board, and staff or Managers and others and experts from the cooperative promotion offices) and secondary source (the review of governance models and pillars of governance, such as accountability) for this study, analyze and present them in a chronological manner.

Sample Size and Sampling Techniques

There were thirty-six (36) cooperative societies in the study area. Among these, four of them are agricultural cooperatives societies. The sample of the study included all the four available Agricultural primary cooperatives from the study area. Kothari (2004) formula was used to determine sample size from these four primary cooperatives.

$$
n=\frac{\text { Z2.p.q.N }}{\mathrm{e} 2(\mathrm{~N}-1)+\mathrm{Z} 2 \mathrm{p} \cdot \mathrm{q}}
$$

Therefore, 123 members as respondents were selected from 198 populations of four Agricultural cooperatives in the Woroda. Stratified sampling techniques were employed to select these 123 respondents from four cooperatives.

\section{Data Collection Tools}

Questionnaire, semi-structured interview, focus group discussion and document analysis (like plan proclamation and policies) were used to collect appropriate data from the respondents in the context of this study. An eleven-page structured questionnaire, which was divided in to nine parts with 120 (23 open-ended and 107 close-ended items) was prepared. Then, 123 copies of the questionnaire were distributed to the respondents but 114 (99 male 
and 15 female) returned the questionnaire. Semi Structured interview schedule was administered to $20 \mathrm{key}$ respondents to elicit information regarding the set objectives of the study. These include three experts and three developmental agents from the respective Woreda, one Zonal expert and totally 10 members from fours were interviewed to know why the cooperatives really choose certain cooperative governance model.

The preparation of the questionnaire and the interview schedule included governance architecture (the framework of the study, the dimension (constitution, administration and management) of stakeholders and pillars. A focused group discussion (FGD) was conducted using the guiding checklist among, totally 12 , members, management committee and control committee of four cooperatives. From each cooperative, one member, one management committee and one control committee were participated. In relation to the document analysis, secondary data, mainly concerning the governance models supposed to be used in Ethiopian cooperatives including legislatives, bylaws and other related document that can show the determining factors on the choice of cooperative governance models was collected from Regional, Zonal, District offices, websites journals and different related documents. Moreover, legislation and strategic related documents like the bylaws, proclamation and their plans were assessed. Furthermore, the researcher has purposely participated in their annual conference held 27/6/2009 to 30/6/2009 E.C to supplement the interview.

\section{Method of Data Analysis}

The study employed both qualitative and quantitative analysis techniques. The data obtained through the questionnaire were tallied, organized, tabulated, analyzed and interpreted in the context of the topic to make the findings as clear as possible for the reader. The context of the topic mainly focuses on the "who of Governance", the "why of governance" and the "what to do governance", in other words, this includes the analysis of 
the role of the members play in the governance of co-operative and the issues influencing the management and the members to choose certain types of governance models.

Descriptive statistics such as mean, weighted mean standard deviation, frequency percentages and ranking methods were used to analyze the objectives to identify why of governance, who of governance, what to do of governance in the process of the application of different governance models. This is because descriptive statistics can help to analyze the first two objectives to infer on the governance architecture and governance models applied by employing frequency and percentage. The third objective was also analyzed on factors that determine the choice of governance models by using descriptive statistics and ranking in order of the models choices of responses given by the respondents.

Result and Discussion

Result

Governance Architecture for Agricultural Cooperative in the District

This section presents information on whether Agricultural primary cooperatives in Ilu Galan District adapted governance architecture/system including the four pillars of cooperative governance: accountability, transparency, predictability and participation. The respondents had given a five alternative responses for each statement to show their agreement using a tick $(\checkmark)$ mark in the space provided for the alternatives. In addition, they were asked to give their reasons for their responses as in the following table.

Table 1: Governance Architecture for Agricultural Cooperative by Percentage

\begin{tabular}{|l|l|l|}
\hline No & Items & Mean \\
\hline 1 & My cooperative has plan. & 4.2 \\
\hline 2 & My cooperative has bylaw. & 4.0 \\
\hline 3 & My cooperative has Vision, Mission and Objectives. & 2.3 \\
\hline 4 & I have been participating in planning processes of my cooperative. & 2.5 \\
\hline 5 & I have been participating in the processes of my cooperative's bylaw. & 2.1 \\
\hline
\end{tabular}




\begin{tabular}{|l|l|l|}
\hline 6 & I feel I am playing my proper role as a member and/or as a committee. & 2.5 \\
\hline 7 & I think I have is good with management and members of the cooperative. & 2.4 \\
\hline 8 & I feel the decision-making processes are made based on the procedure & \\
\hline 9 & & I think my cooperative management is highly transparency. \\
\hline 10 & I think my cooperative management effectively holds responsibility. & 2.6 \\
\hline 11 & I think my cooperative management receive accountability. & 2.3 \\
\hline 12 & I think my cooperative management is participatory. & 2.1 \\
\hline 13 & My cooperative is using cooperative proclamations & 2.6 \\
\hline Grand Mean & 2.4 \\
\hline
\end{tabular}

Table one presents the indicators of to what extent governance architecture/system were physically present in Agricultural Primary Cooperatives of Ilu Galan District. As indicated in the table, the cooperatives have bylaw (4.0) and annual plan (4.2), but they have little knowledge whether the cooperative use cooperative proclamation (2.4), Vision, Mission and Objectives (2.3). Moreover, they hardly know about the cooperatives' principles and values of cooperative and the pillars of cooperative governance such as accountability (2.1), transparency (2.6), predictability (2.5) and participation (2.6). Table 1 also shows the level of members' participation in the cooperative system development. The members rarely participated in planning processes (2.5), bylaw development processes (2.1), decision-making processes (2. 4), and process of management election (2.3). Furthermore, the respondents do not the member thing members effectively perception in the system/ architecture as a member and/or as a committee and as management member.

Governance Models Dominantly Implemented to Agricultural Cooperative

The next section requires information to investigate the cooperative governance models, which Agricultural Primary Cooperatives are dominantly implementing in their context. According to literature, these models include Democratic Model, Compliance Model, Partnership Model, Co-optation Model, Stakeholder Model and Rubber Stamp Model as the dominant perspectives of and practices in cooperatives. Therefore, to investigate the 
dominantly implementing for Agricultural Primary Cooperatives in Ilu Galan District, the respondents were requested to give their answer a 47 questions with five options show whether they strongly disagree (0), disagree (1), undecided (2), agree (3) or strongly agree (4) with each idea. The following table 2 presents the summery of the governance models applied in primary agricultural cooperative in Ilu Galan District.

Table 2: Summary of the Governance Models applied in Primary Agricultural Cooperative by Percentage, Weighted Mean and Standard Deviations

\begin{tabular}{|l|l|l|l|l|l|}
\hline No & $\begin{array}{l}\text { Governance Models } \\
(\mathrm{n}=114)\end{array}$ & SDs & Weighted & $(\%)$ & Rank \\
Mean & & & \\
\hline 1 & Democratic Model & 0.12 & $2 . .66$ & 66.5 & 1 \\
\hline 2 & Compliance Model & 0.22 & 1.74 & 43.5 & 6 \\
\hline 3 & Partnership Model & 0.23 & 2.3 & 57.5 & 4 \\
\hline 4 & Co-optation Mode & 0.46 & 2.5 & 62.5 & 2 \\
\hline 5 & Stakeholder Model & 0.78 & 1.28 & 32.0 & 5 \\
\hline 6 & Rubber Stamp Model & 0.21 & 2.37 & 59.25 & 3 \\
\hline
\end{tabular}

According to the information in table 2, the weighted mean 2.66 shows that more than half $(66.67 \%)$ of the respondents think that their cooperatives were implementing the democratic governance model for its advantages. In other words, although the implementation of democracy and democratic government are central to cooperatives, the mean values of 3.1 and 3.0 shows that $77.5 \%$ of the respondents claim that members are frequently participated in training and management bodies are setting the overall direction to represent the member interests in the cooperative. Similarly, the mean value in the table shows that $70 \%$ of the respondents claim that all cooperative management members are elected by open elections based on one person one vote. The respondents also think that expertise is not a key requirement as it may be in other organization; as a result, the cooperatives put greater emphasis and resources to satisfy the need in the areas of training. The views of the members of the Agricultural cooperatives on this model were indicated in 
the following table 6 .

However, a mean value of 1.6 shows that $40 \%$ of the respondents think that member interest is driving the cooperative activities. This perspective suggests that representation of member interest is not key driver in the job and responsibility of the cooperative management in the area of the study. According to the half (50\%) of the respondents the management body is not resolving the conflict between the interests of different groups. Although democratic representation theory considers that the job of management members is to represent the member interests of the cooperative, The mean value of 2.5 indicates that most of the members $(62 \%)$ of the cooperatives are not participated in in the decision making processes, like making the bylaw and planning processes.

According to the overall mean (1.74) calculated in table 2 above, $43.5 \%$ of the respondents indicate that compliance model or agency theory is not the dominant model to the Agricultural cooperatives in Ilu Galan District. This is because according to the mean value of $1.0,75 \%$ of the respondents do not think that the management is the most important way that members have to control managerial behavior. Similar number of respondents 72.5 also thinks that a majority of the management body of their cooperative are dependent of the other body, unnecessarily intervention of government structure like Kebele leaders. This means that the agency theory basically assumes that the owners of organizations and the management of these organizations have different interests in which governance arrangements are a means by which management (the agents) is encouraged and forced to act in the best interest of the owners. As most $80 \%$ of the respondents nicely stated, cooperative of management bodies should be independent of the external influences. For cooperatives, as analyzed by Cornforth (2004), the board is the most important way that members have to control managerial behavior, but at the same time this board has to operate in a context where it is likely to be more difficult to exert influence. 
Contrary to agency theory or Compliance Model, Partnership Model assumes that managers want to act as effective officers of resources on behalf of owners. Partnership is built on the foundation of stewardship theory. The overall mean (2.3) calculated in table 2 above shows that $57.5 \%$ of the respondents indicate that partnership model or stewardship theory is better in its implementation than compliance model to cooperatives in the District. However, this model is also not the dominant model to the Agricultural cooperatives in Ilu Galan District. The mean value 2.4 indicates that $60 \%$ of the respondents agree with idea that the management members are selected on the basis of their expertise and contacts. The impracticably of this model to the cooperative is because of the fact that Agricultural Primary Cooperatives do not have Boards as per of the proclamation of the country. However, the mean value of 3.0 reveals that $75 \%$ of the respondents claim that the management ideas and practices are applied to governance to improve performance of the cooperatives. Therefore, they are in a position to add value to the cooperative's decisions.

The calculated overall mean value 2.5 in table 2 above shows that the implementation of this theory is better than others next to the democratic model. The overall value 2.5 calculated for the case of co-optation model/ resource dependency theory in table 2 shows that most $(62.5 \%)$ the respondents think that the managements of their cooperatives were doing the main role of the management subscribed in this model. This means the main function of the management according to the model is to maintain good relationships with key non-owner external stakeholders they think in order to ensure the flow of resources (for example fertilizer, anti-herbs and food related goods, oil and sugar) into and from the organization and to help the organization respond to external change. Management members are selected for the important external links and knowledge they can bring to the organization, and try to cooperative external influences. From this perspective the management is part of both the organization and its environment. The detailed information on 
this issue is indicated in the following table 9.

The overall value of 1.28 indicated in table 2 for the implementation of Stakeholder Model Stakeholder shows that only $32 \%$ of the respondents consider stakeholders as the base for cooperative. Besides, although it is expected that cooperatives should be more likely to respond to broader social interests than the narrow interests of one group, only $32.5 \%$ of the respondents feels that their cooperative is responsible to a range of groups besides the members. This means, the management is not incorporating different stakeholders. Moreover, according to most $(82.5 \%)$ of the respondents, political role for the management bodies is not to negotiate and to resolve the potentially conflicting interests of different stakeholder groups in order to determine the objectives of the cooperatives and set policy. The next section also campers the implementation level of Rubber Stamp Model with others.

Literature shows that a rubber stamp model is based on managerial hegemony theory. The calculated overall mean value, 2.37 , shows that this theory is also not the dominant model applied to Agricultural Cooperatives in the District. This theory relates to the premise that control of organizations has really passed from owners to a new professional managerial class. According to the data (2.3) in the table $57.5 \%$ of the respondent claim that the management bodies are simply symbols to pass decisions. In other words, they are essentially symbolic to give legitimacy, legality, validity for the paid workers' actions. The finding of this study is consistent with results identified by Berle and Means' (1932) in that although members of the cooperatives legally own and control large corporations, they no longer effectively control them. In addition, they make reference to some works about the decision. Herman (1981) came to similar conclusions but argued that managerial power was always in the context of various constraints and the latent power of stakeholders such as external board members. In summary, although the implementation of this model is better than others, the result shows that the performance still leave much room for improvement. 
Determining Factors for the Choice of Application of Cooperative Governance Models

It is adequately documented that initial preference of the members to their cooperative is a factor for future commitment and job satisfaction for the members. Higher commitment may be higher among the members who were initially attracted to the cooperative. Thus, this variable was roughly assessed based on a single item. Accordingly, the members were asked to indicate why they became the members of their cooperatives to evaluate their commitment to their cooperatives by making a think $(\sqrt{ })$ mark under the alternative against each statement given as in table 3 below.

Table 3: The Summary of Factors Determining the Choice of Application of governance Models

\begin{tabular}{|l|l|l|l|l|}
\hline No & Factors & SD & Overall & Mean \\
\hline 1 & Teaming factors & 0.21 & 6.21 & 4 \\
\hline 2 & Leadership factors & 0.23 & 6.01 & 5 \\
\hline 3 & Conflict of Interest and Dominance Over the & 0.21 & 6.40 & 3 \\
\hline 4 & Other & & & \\
\hline 5 & Legal Related Factors & 0.46 & 6.12 & 6 \\
\hline 6 & Governance Factors & 0.26 & 5.60 & 7 \\
\hline 7 & Lack of Awareness/Education/Training & 0.23 & 6.50 & 2 \\
\hline
\end{tabular}

As it is already indicated above, it was intended to see the member's commitment to the cooperative as a precursor (anticipating) of future likelihood of their satisfaction in the job. The overall mean value (1.6) calculated in table 3 reveals that the initial commitment of the stakeholders to their cooperative is low. Specifically, table 3 indicates that the mean value 
(2.7) shows that most $62(54 \%)$ of the members had joined the cooperative to get money like their friends because of the fact that they (35\%) could not get another occupation as an alternative, and it is the kind of job that they (40\%) could easily get. Moreover, greater number of $(57.5 \%)$ of the respondents also claimed that they became members because the kebele leaders forced to be the member of the cooperative it had organized. In contrary, the mean value of 0.8 indicates that very few 20(17.5\%) members selected the cooperative as a career for its attractive nature by that time. Therefore, it may be anticipated that lack of interest in the cooperative affected the choice of the right cooperative governance models.

All the 114 respondents' form the four agricultural cooperatives were also asked to respond to the question if they have choice whether will leave their cooperative or not. The responses of the respondents show that $88(77.2 \%)$ i.e. $81(81.82 \%)$ male and $7(46.67 \%)$ females want to leave the cooperative if they get other alternatives. They also mentioned some reasons for their desire to leave the cooperatives. The reasons are: lack of good dividend and other income, inefficient administration (internal and external to the cooperative), unnecessary interventions of kebele leaders for political reasons, lack of clear unity of command and unity of direction, lack of personal freedom, lack of respect and recognition, social services, job protection and poor management members' character.

Pillars of good governance determine the choice of the cooperative governance models. As it has already been stated above, lack of transparency to access information (3.39), accountability (3.36) and low socio-economic services for members (3.08) are the first three most important factors for the choice of certain governance model. Moreover, lack of democratic decision-making process (3.05), lack of predictability and regularity (3.00) and irresponsibility (2.99) are the second most important reasons for the cooperatives managements and members to choose certain model. Furthermore, lack of fairness and equitably (2.96), poor relationship between management and members (2.80) and lack of 
equal commitment among members for the cooperative (2.72) are the third important factors for the members to choose the models. Finally, irrelevant information (2.13), poor relationship between members and paid workers (2.41) and low level of member participation (2.60) are turned out to be the least important factors of the choice.

Table 3 presents the evaluation of the Stakeholders' Commitment and Strategic Leadership as the factors for the choice of certain governance models for Primary Agricultural cooperative. The data in the table reveals that ineffective strategic leadership affected the choice of cooperative governance model in the district for the cooperative under investigation. According to the information in table 3 above, the strategic leadership ability (1.3) and the commitment of the stakeholders in general is low. almost half $(70 \%)$ of the respondents think that ability to set and communicate vision (0.95), mission (1.1), and direction (1.7 )as well as the ability o mobilize the cooperative society(0.9) towards the goal of the cooperative affected the choice of the model. The management of the cooperatives was also ineffective in setting and communicating the cooperatives' objectives (1.8), purpose (1.6) and activities (0.9). respondents were also asked to evaluate the commitment of the stakeholders in their cooperatives. As result more than half $(57 \%)$ of the respondents claim that government structure (1.2\%) commitment was better than that of members (1.1), paid worker including managers (1.1) and managing committees (1.0) in their commitment to their cooperatives.

Teaming refers to the activity of the stakeholders to successfully working together to achieve common purpose. However, according to most of the respondents the level of team sprite is judged as low because the weighted mean value of the teaming factor is 2.3 . Specifically, common goal commitment (1.1), relationship (2.1) and common excellence (3.3) for their cooperative are still low, which in turn may affect the choice of the appropriate cooperative governance model. Normally, the management body is responsible for 
perpetuating the excellence and for organizing and managing its own cooperatives' works. The management must work together effectively as a team to make this possible. This includes having a common agreement about the work, clear expectations of individuals and the group itself, an effective decision-making system, and effective leadership of the group.

The cooperatives have different choices of applying various models of governance to govern their affairs. In this context, the governance models applications choice would be Models based on structure or function (the who of governance), Models based on motives or behavior (the why of governance) and Models based on prescription and best practices (what to do of governance). In the same token, this refers to the analysis of the role of the management, members, non-members play in the governance of co-operative and the issues influencing them to choose certain types of governance models. The respondents were asked to rank the determinant factors. According to the responses of the respondents, the mean value in brackets show that governance Factors(6.60), lack of awareness/education/training(6.50), Teaming factors (6.21) and leadership factors ((6.01) are the top four factors in influencing the choice of the application of cooperative governance models to primary Agricultural cooperatives in the District.

The cooperative do moreover not use legal frameworks prescribed in the proclamation and bylaw. Teaming factors such as commitment, group culture, common excellence, common agreement, common expectations, group leadership and power as a unit are also identified as determinant factors for the subject. Furthermore, poor strategic leadership, which means poorly setting visions, missions and objectives, cooperative's directions, plan cooperatives' purpose for social mobilization have contributed for the problem. Still lack of proper role play of stakeholders (managing committee, controlling committee, members, manager and other employed) are also factors for the choice of the application of cooperative governance models to primary Agricultural cooperatives in the District. 


\section{Discussion}

This discussion section includes all the data obtained through the instruments such as questionnaire, document analysis, interview and FGD. For the last two decades in Ethiopia in general and in Oromia in particular the government has been organized cooperative structure from the federal to kebele level. The structure has also been working for the empowerment of different types of cooperatives to reduce poverty in the country. To this end, the governance has indispensable roles. Researchers also conducted different studies on different aspects of governance. However, prompted by increased concern about the cooperative governance models, the study was conducted to analyze the architecture, the application and the factors determines the choice of governance models applied in Primary Agricultural Cooperatives in Ilu Galan District. As a result, based on the data analysis made so far, the following findings were summarized below.

To begin with, the characteristics of the respondents by sex, age, and marital status, length of years as membership and level of income were analyzed. The information shows that all the cooperatives were male dominated organization. In relation to the governance model, both the cooperatives' bylaws and annual plans did not clearly indicate the vision, mission and objective, as well as the role and responsibilities of management committees. Moreover, the management bodies, members and experts from Worada level including DAs do not know the cooperative governance models. Moreover, from 123 members of the cooperatives selected on the basis of random sampling techniques, 114. i. e. $99(86.8 \%)$ male and $15(13.2 \%)$ female respondents were available for the self-administered interview. The existing members of the cooperative seem to be older in their age. For instance, $101(88.6 \%)$ of the members were more than 40 years old, whereas only $13(21.4 \%)$ of them were less than 40 years old. The median age of the members is 38 years. In relation to their marital status, 108(94.7\%), 95(96\%) male and $13(86.7 \%)$ female of the members were married but 
only $7(6.1 \%), 3(3 \%)$ male and $4(26.7 \%)$ female of the members were divorced/widowed during the data gathering time for this study.

The results of the study mainly show that Agricultural primary cooperatives in Ilu Galan District have tried to adapt the governance architecture. In other words, all the cooperatives have plan but only two of them have bylaw. However, all the plans of the cooperatives cannot clearly indicate the vision, mission, objectives and activities to be achieved. Moreover, the bylaws of the cooperatives do not also clearly show the governance framework or the four pillars: accountability, transparency, predictability and participation.

As it is already indicated, the data analyzed show that almost all the members of the cooperatives were confused with word "model". They hardly apply the principles of cooperatives in general and that of governance models in particular. Democratic (2.66), Co-optation (2.5), Rubber Stamp Models (2.37) were the top three models that Agricultural Primary Cooperatives were implementing in the District. On the other hand, Compliance (1.74), Stakeholder (1.28) and partnership (2.3) were turned out to be the three least implemented cooperative governance models.

For a number of different reasons, cooperatives try to avoid hierarchical structures. The decision-making structure in such organizations is typically labeled "peers management" or "collective governance". In Democratic governance Model all responsibility is expected to be shared, and there is no Chief Executive Officer. In other words, decision-making is normally by consensus and no individual has power over another. However, as per the law or different proclamations, Agricultural cooperatives do not have a board of directors at primary level. Therefore the cooperative strives to fit the management into its organizational philosophy by creating a single managing body composed of seven members.

The data indicates the most important issue for most (75\%) of the respondents is the profit they expect from their cooperatives. dependency as its foundation. The role of the 
board is one of spanning boundary. The data also gathered through interview and FGD shows the standpoint of this theory that the management is seen as a way of reducing uncertainty by creating influential links to the externals, for example, the Worada cooperative promotion offers, Worada and Kebele political leaders.

Stakeholder Theory is the base for stakeholder Model. This theory suggests that cooperatives should be responsible to a range of groups besides the owners. From this perspective, the management is characterized by incorporating different stakeholders. In summary, in cooperative perspectives on governance, as the most democratic style of management, though it is, perhaps, the most difficult of all models to maintain all requirement, the cooperatives under the question have limitations in a shared sense of purpose, level of commitment by all group members, a willingness to accept personal responsibility for the work of others, and an ability to compromise conflicts involving all the members in decision-making. The next section discusses the implementation of Compliance Model in the cooperatives' activities.

Analyzing the third objectives, the factors determining the choice of application of cooperative governance models to primary Agricultural cooperatives in the District are respectively lack of democratic decision-making process (lack of predictability and regularity and irresponsibility, transparency to access information, accountability, unnecessary intervention of local leaders improper role play and other governance related factors, lack of awareness/education/training, teaming and strategic leadership, lack of initial commitment to the cooperative, Conflict of Interest and dominance over the other etc.

As it has already been stated above, Democratic (2.66), Co-optation (2.5)and Rubber Stamp Models (2.37) were the top three the Agricultural Primary Cooperatives were implementing in the District. On the other hand, Compliance Model (1.74), Stakeholder Model (1.28) and Partnership Model (2.3) were turned out to be the least implemented 
cooperative governance models. According to 76 (66.67\%) of the respondents, cooperatives are implementing democratic governance model for its advantages. For a number of different reasons, cooperatives try to avoid hierarchical structures. The decision-making structure in such cooperatives is typically labeled "peers management" or "collective governance". The qualitative data collected through FGD and interview also indicate that the political situation and the direct involvement of the local government structure (Woreda and Kebele Leaders) influenced the cooperatives to implement more democratic model's features than others.

The focus of the governance debate was on issues relating to structural governance (because the primary cooperatives do not have board of governance) and on the challenge of participatory decision-making. There was hardly any discussion on how the cooperatives progress and transformation by the management body. The respondents also complain on the improper role of management bodies because they sometimes involve in the multi-folding processes.

The findings from key informants and FGD also show similar results with the above findings. The governance debate was on issues relating to structural governance (because the primary cooperatives do not have board of governance) and on the challenge of participatory decision-making. The respondents also complain on the improper role of management bodies because they sometimes involve in the multi-folding processes. The respondents complained the relationship between cooperatives and the government that local political cadre has a peculiarly mixed (abnormal, paradoxical, inconsistent and contradictory) role. In general, the respondents commonly perceived that there is little or no autonomy in the cooperative governance to apply certain cooperative governance model to the cooperatives.

According to the data, the reasons advanced for becoming members of the cooperative were mostly extrinsic to the cooperative. That is, according to the respondents, lack of other alternative job that they could easily get to earn money like their friends was 
ranked as the most important reasons. However, some members were assigned/ organized to the cooperative by their respective Kebele leaders without their interest. This may lead to say that some of the members may refuse to receive responsibilities in the cooperative which in turn may affect the choice of cooperative governance model.

To discuss some points, the reasons for poor relationship between members and manager, for example, include: conflict interest, low awareness about their role, lack of interest in taking role, more advantageous gained from other personal activities, poor attentions to members concern, members are not democratically treated lack of transparency and poor understanding of cooperative proclamations. The unnecessary involvement of the government structure in the cooperative activities is also another factor to choose the model. This is because of the fact that the government uses the cooperative as political affiliation and without the government intervention, success is possible. The respondents complain that the government intervention affected the concept that cooperative is self-controlled and selfcovered organization. However, the management members of the cooperatives work for the government interest because they expect more benefits from the government. Reasonably, most $(89 \%)$ of the respondents of this study claimed that they want the government intervene in their cooperatives in administrative and financial (provide credit), technical support and in legal assistance.

The information in this table 3 implies that the stakeholders of the cooperatives need to have power as a unit. An individual chairperson has only power, beyond that of any other co-op owners, is the ability to influence the management group. Diversity of opinion is necessary and valuable. Yet the group must have the ability to think and learn together, to come to a decision and support that decision. The managing committees must also create and maintain a group culture that supports their work. Viewed through the lens of the four pillars 
of cooperative governance, self-responsible teaming is the first step for management effectiveness.

In simple words, the management of the cooperatives was unable to ensure the pillar of governance: transparency, responsibility predictability, participatory and accountability. Similarly, low level of educational background, insufficient training and lack of team commitment for members and management affected the choice of the application of cooperative governance models to primary Agricultural cooperatives in the District.

\section{Conclusions}

On the basis of data analysis made so far, the most difficult issue in the cooperative governance were the problems of defining the roles and responsibilities of stakeholders: local government structure, management committee, controlling committee, managers and other paid workers as well as members and non-members stakeholders. This confusion with the system, principles and values of cooperatives of cooperative has created individuals dominated governance or improper role play among the stakeholders of the PACs in the District. Lack of awareness about legal frameworks prescribed in the proclamation and bylaw to ensure the pillar of governance: transparency, responsibility predictability, participatory and accountability in their bylaw and in their practical activities as well as to set relevant and appropriate visions, missions, objectives and directions in their cooperatives' affected the architecture of the cooperatives and choice of the application of the cooperative governance model. However, the management committees of the cooperatives were implementing relatively more democratic governance model than others for the current political situation. Low level of educational background, failure of democratic governance and the increase in corruption across the cooperative societies, insufficient training and lack of team commitment for members and management were identified as determinant factors for the choice of the 
application of cooperative governance models to PAC and witnessed the dissatisfaction with the cooperative governance in general.

\section{Recommendations}

1. The cooperative officers and experts from West Showa Zone and Ilu Galan District are expected to train the cooperative management committees (including controlling committee, managers and other paid workers) and non-members stakeholders and the members at large on the legal frameworks, the principles and values of cooperative as well and on the cooperative governance pillars to develop their team spirit so as to they can mobilize the he cooperative society towards the goal of the cooperatives.

2. The cooperative officers and experts from West Showa Zone and Ilu Galan District are expected to support the cooperative management committees on how to encourage the member to participate in the process of different types of planning (including the clear and relevant vision, mission, objectives and direction) and setting bylaw with clear indication of the governance pillars.

3. The cooperative promoters at all level should give contentious basic training to minimize the confusions in the system of cooperative, difficulties and problems of defining the roles and responsibilities of stakeholders, which in turn avoids the individually dominated governance or improper role play among the stakeholders of the PAC in the District.

4. The management bodies of the cooperatives in the District should use different cooperative legal frameworks prescribed in the proclamation and bylaw to ensure the pillar of governance (transparency, responsibility predictability, participatory) and to minimize the dominance and the conflict of interest among individuals and/or groups.

5. The local political leaders should make the cooperatives governance systems from political affiliations so as to they can focus on their own socio-economic problems. 
6. The management committees of the cooperatives must be more democratic than they were to apply more Democratic governance model/feature for a number of different advantages.

7. Members of the cooperatives must learn the difference between the principles and values of corporate and cooperative to avoid unexpected expectations from cooperative. 


\section{References}

Bhagwati, P.. (2003). "Some Dimensions of Cooperative Governance", the Cooperator, 41(3), Bhoria. K.S. (2002). "Cooperative Governance with particular reference to India", The Cooperator, 40(6), NCUI: New Delhi.

Bruun, A. (2002). Contemporary co-operative governance, Canadian co-Operatives association: Institute of Co-operative Studies 28-30, Kelowna, British Columbia. Canadian Non-Profits (Ottawa: Institute on Governance,)

Carver, J. (1997). Boardst hat Make a Difference: Anew Design for Leadership in non-profit and Public Organizations: San Francisco

Cornforth, B. (2002) John Carver on Board Leadership: Selected Writings from the Creator of the World's Most Provocative and Systematic Model.

Cornforth, Ch. (2002). "Making Sense of Co-operative Governance: Competing Models and

Cornforth. (2004) Corporate Boards that Create Value: Governing Company Performance from the Boardroom.

Dunteman, G. H. (1989). Principal components analysis. Newbury Park, CA: Sage Publications.

Garber, N. (1997) Governance Models: What's Right for Your Board? : 1071 Richmond Street, London, Ontario, Canada N6A 3K1 tel: (519) 670-4256 Skype: Nathan. Garber Nathan Garber \& Associates email: nathan@GarberConsulting.com

Gill, M.(2002) Governance Dos and DON'Ts: Lessons from Case Studies on Twenty Houle, Cy. (1997). Governing Boards: Their Nature and Nurture(Prentice-Hall,) Karthikeyan. M. (2008). Cooperative Governance - Training Manual, England Africa Partnership Project (British Council, UK), Ambo University College, Ambo, Ethiopia. Manly, B.F.J. (2005), Multivariate Statistical Methods: A primer, Third edition, Chapman and Hall. NCUI: 
Oliver, C.. (1999) The Policy Governance Field book: Practical Lessons, Tips and Tools from the Experience of Real- World Boards (San Francisco: Jossey-Bass,) Tensions" in Review of International Co-operation, V.95\#1 (Geneva: ICA,)

Rencher, A.C. (2002), Methods of Multivariate Analysis, Second edition, Wiley. 